\title{
BORO DISPONÍVEL E RESPOSTA DA SOJA EM LATOSSOLO VERMELHO-AMARELO DO MATO GROSSO ${ }^{(1)}$
}

\author{
Ciro Antonio Rosolem ${ }^{(2)}$, Leandro Zancanaro ${ }^{(3)} \&$ Thaís Bíscaro $^{(4)}$
}

\begin{abstract}
RESUMO
Em observações de campo, muitas vezes não tem sido possível detectar diferenças nos teores de B no solo com a aplicação de adubos boratados, embora os teores do nutriente nas folhas apresentem resposta, havendo dúvidas quanto à eficiência do método de extração normalmente utilizado. Neste trabalho, foi avaliada a disponibilidade de B em Latossolo Vermelho-Amarelo do Mato Grosso com três extratores, procurando-se correlacionar as respostas da planta às doses de $\mathrm{B}$ aplicadas. Doses de 0, 1, 3, 5, 7 e $10 \mathrm{~kg}^{-1} \mathrm{ha}^{-1}$ de $\mathrm{B}$ foram aplicadas em experimento com doses de 1,5, 3, 4,5, 6, 7,5 e $9 \mathrm{t} \mathrm{ha}^{-1}$ de calcário, em soja cultivada por três anos. A cada ano foram tomadas amostras de solo, da camada de $0-15 \mathrm{~cm}$ de profundidade (camada arável) e de folhas no florescimento da soja. Para as análises de $\mathrm{B}$ do solo, foram utilizados três extratores: $\mathrm{CaCl}_{2}, \mathrm{BaCl}_{2} \mathrm{e}_{2} \mathrm{O}$ quente tradicional. A soja respondeu à calagem e ao $\mathrm{B}$ aplicado a partir do segundo ano do experimento, mas as respostas não foram correlacionadas com os teores foliares de B. O extrator que apresentou maior consistência de regressões significativas entre teores no solo e nas folhas, nas três safras, foi o $\mathrm{CaCl}_{2}$. Entretanto, nenhum dos extratores discriminou a possibilidade de resposta da soja ao $\mathrm{B}$, assim como não foi possível proceder à calibração dos resultados de modo a estabelecer faixas de resposta, uma vez que não houve correlação dos teores no solo com a produtividade.
\end{abstract}

Termos de indexação: adubação, análise de solo, calagem, extratores, fertilidade do solo, micronutrientes.

\footnotetext{
(1) Parte da Dissertação de Mestrado da terceira autora, financiado pela FAPESP. Recebido para publicação em dezembro de 2007 e aprovado em outubro de 2008.

(2) Professor Titular, Departamento de Produção Vegetal, Faculdade de Ciências Agronômicas, UNESP. Caixa Postal 237, CEP 18603-970 Botucatu (SP). Pesquisador do CNPq. E-mail: rosolem@fca.unesp.br

(3) Engenheiro-Agrônomo, MSc., Fundação MT. Av. Antonio T. dos Santos 1559, CEP 78750-000 Rondonópolis (MT). E-mail: leandrozancanaro@fundacaomt.com.br

(4) Mestranda, Curso de Pós-Graduação em Agricultura, Faculdade de Ciências Agronômicas, UNESP. E-mail: tbiscaro@fca.unesp.br
} 


\title{
SUMMARY: EVALUATING AVAILABLE BORONAND SOYBEANRESPONSE TO BORON IN AN OXISOL FROM CENTRAL-WESTERN BRAZIL
}

\begin{abstract}
Based on field observations it is often impossible to detect differences in soil B contents after the application of $B$ fertilizers, even when increased leaf $B$ contents are detected. This has raised doubts as to the efficacy of the $B$ extractor used in routine soil $B$ determinations. An experiment was conducted to study $B$ extraction and availability to soybean in an Oxisol in the state of Mato Grosso. Boron (as boric acid) doses ranging from 0.0 to $10.0 \mathrm{~kg} \mathrm{ha}^{-1}$ were combined with lime rates from 1.5 to $9.0 \mathrm{t} \mathrm{ha} \mathrm{h}^{-1}$. Soybean was grown for three years. Soil samples were taken from the $0-15 \mathrm{~cm}$ (arable) layer and leaf samples were collected at soybean flowering each year. Boron was extracted using $\mathrm{CaCl}_{2}$ and $\mathrm{BaCl}_{2}$ solutions and the traditional hot water. Soybean responded to lime and $B$ from the second year onwards, but the response was not correlated with foliar B concentrations. In the three growing seasons leaf boron was best related with soil B contents extracted with $\mathrm{CaCl}_{2}$. However, no extractor differentiated the possible soybean response to $B$ and it was not possible to establish soil B levels as low, medium or high as related to soybean response since the soybean yields were not correlated with the soil B levels.
\end{abstract}

Index terms: extractors, fertilization, liming, micronutrients, soil analysis, soil fertility.

\section{INTRODUÇÃO}

O uso de micronutrientes na agricultura brasileira, de 1992 a 2004, teve um aumento de $1.300 \%$ chegando o consumo a 700 mil toneladas, entre eles o B (Pinazza \& Borsari, 2004). Entretanto, esse crescimento não foi acompanhado pelo desenvolvimento de métodos confiáveis para a recomendação de adubação com esses nutrientes.

Na determinação do B disponível no solo, têm sido utilizados extratores como água quente, soluções de sais, de ácidos, agentes complexantes e combinações de reagentes (Fontes et al., 2001). A água quente (Berger \& Truog, 1944) tem sido usada como padrão na avaliação de outros métodos e consiste em se fazer a extração usando sistema de refluxo, com filtragem imediata. Este método tem sido considerado superior aos que utilizam soluções salinas, ácidos fortes diluídos e soluções complexantes para a extração do B disponível no solo (Cruz \& Ferreira, 1984; Silva \& Ferreira, 1999), embora inexistam informações que possam ser generalizadas. A morosidade do método, dificuldades operacionais e a possibilidade de perda de $\mathrm{H}_{3} \mathrm{BO}_{3}$ na forma de vapor são alguns problemas associados (Fontes et al., 2001). Ainda, com relação à definição conceitual de $\mathrm{B}$ disponível nos solos ácidos, a extração com água quente deixa a desejar (Offiah \& Axley, 1993).

Com o objetivo de eliminar a ebulição sob condensador de refluxo, foi proposta agitação da suspensão solo-água por cinco minutos em banhomaria a aproximadamente $70^{\circ} \mathrm{C}$ (Cruz \& Ferreira, 1984). Os autores obtiveram correlação significativa entre o método convencional e a técnica modificada, e também entre o B extraído pelas plantas e aquele extraído por meio do método modificado. De qualquer modo, os resultados obtidos com extração em água quente têm sido contraditórios. Robertson et al. (1975) obtiveram correlação significativa entre o B no solo e na planta, mas Martens (1968) e Parker \& Gardner (1982) observaram ausência de correlação entre B extraído pela água quente e o extraído pela planta ou produção.

A determinação do B extraído com água quente, seguida da análise de $\mathrm{B}$ com azometina- $\mathrm{H}$, segundo Fontes et al. (2001), pode apresentar turbidez nos extratos devido à presença de material coloidal. Isso pode ser contornado com a adição de $\mathrm{CaCl}_{2}$ para flocular as partículas coloidais, facilmente removidas por filtração. Na determinação de B por espectroscopia de emissão atômica acoplada em plasma induzido (ICP-AES), a adição de $\mathrm{BaCl}_{2}$ é importante para impedir o entupimento dos capilares de sucção do aparelho devido às partículas coloidais. Além disso, colorações nos extratos devido à presença de componentes orgânicos também podem interferir na análise. A adição de carvão ativado para descolorir os extratos pode ser usada para contornar esse problema.

Além da água em ebulição, o $\mathrm{B}$ disponível dos solos pode ser extraído por meio de soluções ácidas e salinas. Soluções ácidas como ácido clorídrico, ácido acético (Li \& Gupta, 1991), ácido sulfúrico (Bartz \& Magalhães, 1975) e solução de Mehlich-1 (Ribeiro \& Tucunango Sarabia, 1984) também têm sido usadas como extratores de $\mathrm{B}$ dos solos. Independente do método de extração, a presença de Fe nos extratos pode interferir no resultado quando se usa azometinaH na análise do B. Em solos de Minas Gerais e Mato Grosso do Sul, foi observada forte interferência do Fe na extração com $\mathrm{HCl} 0,05 \mathrm{~mol} \mathrm{~L}^{-1}$, vindo a seguir a extração com Mehlich-1 e, por último, a extração com 
HCl 0,1 mol L-1 (Ferreira, 1998). Não houve correlação entre os teores de B extraídos por soluções ácidas e por água quente. A adição do ácido tioglicólico aos extratos, para a eliminação da interferência do $\mathrm{Fe}$ (Zarcinas, 1995) resultou em dificuldades na estabilização da cor do extrato, de modo que, neste caso, a extração tradicional com $\mathrm{HCl}$ mostrou-se preferível à extração com adição de ácido tioglicólico (Ferreira, 1998). Em solos do Canadá, Li \& Gupta (1991) concluíram que o $\mathrm{HCl} 0,05 \mathrm{~mol} \mathrm{~L}^{-1}$ foi superior à água quente, sendo recomendado para estimar o $\mathrm{B}$ disponível para as plantas nos solos ácidos daquela região.

A análise de $\mathrm{B}$ em solos ácidos é claramente alterada por fatores como $\mathrm{pH}$, textura, matéria orgânica e mineralogia. Quanto mais esses fatores variarem de solo para solo, mais a liberação de B pelo solo refletirá essas variações. O extrator Mehlich-1 não consegue discriminar o efeito da calagem na variação do B disponível no solo, ao contrário do que ocorre com a extração com água quente (Bataglia \& Raij, 1990). Dessa forma, as extrações de B do solo com soluções de $\mathrm{BaCl}_{2}$ ou $\mathrm{CaCl}_{2}$, em sacos plásticos aquecidos em forno de microondas, têm sido utilizadas com sucesso (Abreu \& Abreu, 2001; Ferreira et al., 2001).

$\mathrm{Na}$ extração de $\mathrm{B}$ com soluções de $\mathrm{CaCl}_{2}$ e $\mathrm{BaCl}_{2}$ também foram verificadas interferências quando se usou azometina-H, que foram suprimidas pela adição de carvão ativado (Ferreira, 1998). Nas extrações com soluções salinas, sem carvão ativado, o autor sugere que houve interferência das argilas porque a sua baixa atividade dificultou a ação floculante dos íons em solução. Na determinação por ICP-AES, a matéria orgânica do extrato não representa problema, mas o material coloidal pode causar entupimento nos capilares de sucção do aparelho. Entretanto, a extração com $\mathrm{BaCl}_{2} \cdot 2 \mathrm{H}_{2} \mathrm{O} 5 \mathrm{mmol} \mathrm{L}{ }^{-1}$, sem carvão ativado, permitiu bons resultados na análise de $\mathrm{B}$ por ICP-AES (Abreu et al., 1994).

Em análises de solo de áreas comerciais, bem como em experimento de calibração de B realizado em solo argiloso, no município de Campo Novo do Parecis, MT, não foi possível detectar diferenças nos teores do nutriente no solo com a aplicação de 0 a $10 \mathrm{~kg} \mathrm{ha}^{-1} \mathrm{de}$ B. Desta forma, foi levantada a hipótese de que o método da água quente para a determinação do B não estaria sendo adequada (Fundação MT, 2002).

Neste trabalho foi avaliada a extração de B com três extratores, procurando correlacionar as respostas da planta ao B aplicado, associado à calagem, em Latossolo Vermelho-Amarelo do Mato Grosso.

\section{MATERIAL E MÉTODOS}

Foram utilizadas amostras da camada superficial (0-15 cm) de um Latossolo Vermelho-Amarelo distrófico, argiloso (Embrapa, 1999), de Campo Novo do Parecis, MT, provenientes de experimento no qual foi cultivada soja por três anos consecutivos (1998/ 1999, 1999/2000, 2000/2001) e posteriormente algodão (2001/2002). O volume de chuvas da região estudada é de aproximadamente $2.000 \mathrm{~mm}$ por ano, e a altitude é de $650 \mathrm{~m}$. Foram aplicadas doses de B $(0,1,3,5,7 \mathrm{e}$ $\left.10 \mathrm{~kg} \mathrm{ha}^{-1}\right)$ e de calcário $\left(1,5,3,4,5,6,7,5\right.$ e $\left.9 \mathrm{t} \mathrm{ha}^{-1}\right)$, com quatro repetições, no primeiro ano agrícola, sendo o B, na forma ulexita com $150 \mathrm{~g} \mathrm{~kg}^{-1} \mathrm{de} \mathrm{B}$, aplicado a lanço e incorporado. A cada ano, a soja foi adubada com $120 \mathrm{~kg} \mathrm{ha}^{-1}$ de $\mathrm{P}_{2} \mathrm{O}_{5}$ e $100 \mathrm{~kg} \mathrm{ha}^{-1}$ de $\mathrm{K}_{2} \mathrm{O}$ nas formas de superfosfato simples e cloreto de potássio.

Amostras de terra foram coletadas a cada ano, antes da semeadura da soja. Cada amostra composta compreendeu oito amostras simples por parcela, coletadas na profundidade $0-15 \mathrm{~cm}$, como é usual no Mato Grosso. As amostras foram tomadas apenas em uma profundidade, representativa dos métodos utilizados no Mato Grosso, uma vez que a hipótese era que o método de análise de $\mathrm{B}$ em uso não estaria representando as adubações realizadas. Cada amostra foi analisada por três métodos: água quente modificada ou $\mathrm{BaCl}_{2}$, $\mathrm{B}$ solúvel em solução de $\mathrm{CaCl}_{2}$ a quente, e método da água quente tradicional.

Para o método da água quente modificado ou $\mathrm{BaCl}_{2}$ a quente, $10 \mathrm{~cm}^{3}$ de solo foram acondicionados em sacos plásticos de $12,5 \times 26 \mathrm{~cm}$ e, em seguida, foram adicionados $20 \mathrm{~mL}$ de solução extratora de $\mathrm{BaCl}_{2}$ (1,25 g de $\mathrm{BaCl}_{2} 2 \mathrm{H}_{2} \mathrm{O}$ em $1 \mathrm{~L}$ de água). Em seguida, os saquinhos foram selados na altura de mais ou menos $15 \mathrm{~cm}$, sendo feito um pequeno furo no canto superior. Em seguida, foram acomodados para aquecimento em forno de microondas. Foram aquecidos por quatro minutos na potência máxima $(700 \mathrm{~W})$ e por cinco minutos na potência média $(490 \mathrm{~W})$. A temperatura de aquecimento foi determinada de acordo com a potência do forno de microondas utilizado, seguindo o método de Abreu \& Abreu (2001). A suspensão foi deixada em repouso para esfriar por cerca de 30 min e filtrada imediatamente, utilizando-se papel filtro Whatman 42, filtragem lenta, faixa azul. As amostras foram acondicionadas em recipientes plásticos e o B foi determinado por ICP-AES.

Para o método do $\mathrm{B}$ solúvel em solução de $\mathrm{CaCl}_{2}$ a quente, o processo foi idêntico ao do $\mathrm{BaCl}_{2}$ já descrito, porém a solução extratora foi modificada, sendo substituído o $\mathrm{Ba} \mathrm{Cl}_{2}$ pelo $\mathrm{CaCl}_{2}$.

Para o método da água quente tradicional, também foram coletadas amostras de $10 \mathrm{~cm}^{3}$ de solo, sendo adicionados $20 \mathrm{~mL}$ de água deionizada. As amostras foram colocadas em recipientes de teflon cobertos com vidro de relógio (acrílico). Em seguida, foram levadas à fervura em banho de areia, em temperatura de 130 a $140{ }^{\circ} \mathrm{C}$, sob refluxo, durante cinco minutos. Depois de frias, foram adicionadas cinco gotas de solução de $\mathrm{CaCl}_{2}$ a $0,1 \mathrm{~mol} \mathrm{~L}^{-1}$, e o extrato foi filtrado através de papel filtro Whatman 42 (filtração lenta). O B na solução foi determinado por ICP-AES. 
Quando a soja se encontrava no estádio R2, foram coletadas amostras para a diagnose foliar, coletandose 30 folhas recentemente maduras por parcela. $\mathrm{O}$ material foi seco em estufa com circulação de ar a $65^{\circ} \mathrm{C}$ por três dias e moído. Em seguida, o B foi determinado por ICP-AES, como descrito em Malavolta et al. (1997).

O delineamento experimental foi fatorial $6 \times 6$, com quatro repetições em blocos inteiramente casualizados. Foram ajustadas regressões entre os resultados obtidos para concentrações de B no solo com as doses aplicadas, com a produtividade da soja e com os teores de B nas folhas de soja.

\section{RESULTADOS E DISCUSSÃO}

A produtividade de soja foi crescente nos três anos, principalmente devido às melhores condições de fertilidade do solo com P e K (Quadro 1) e, ao contrário do que seria esperado, não foi observada interação significativa da adubação boratada com a calagem. A falta de interação pode ser explicada em função de, segundo Rosolem \& Bíscaro (2007), mesmo com doses relativamente altas de calcário, a adsorção de $\mathrm{B}$ pelo solo ser importante somente no ano em que é realizada a calagem, de modo que, com o tempo, maior quantidade de B fica na solução do solo, em condições de ser absorvido pelas plantas. No primeiro ano, não foi observada resposta à calagem (Figura 1a), provavelmente porque havia limitação por outros nutrientes como $\mathrm{P}$, uma vez que os teores foliares deste nutriente encontravam-se, em média, abaixo de 2,0 $\mathrm{g} \mathrm{kg}^{-1}$ (Bíscaro, 2005), valor considerado baixo (Rosolem, 2007). No segundo e terceiro anos, com a melhoria da disponibilidade de $\mathrm{P}$ e $\mathrm{K}$, houve resposta à calagem até 4,5 e $3,0 \mathrm{t} \mathrm{ha}^{-1}$, respectivamente (Figura 1a).

No terceiro ano do experimento, assim como para a produção acumulada nos três anos, houve resposta ao B aplicado até $1 \mathrm{~kg} \mathrm{ha}^{-1}$ (Figura 1b). É interessante notar que, nos três anos, mesmo no tratamento sem $\mathrm{B}$, os teores do nutriente nas folhas encontravam-se dentro da faixa considerada adequada para altas produtividades (Rosolem, 2007), ou seja, de 25 a
$55 \mathrm{mg} \mathrm{kg}^{-1}$ (Figura 2). Assim, os teores das tabelas de suficiência, embora geralmente aceitos, apresentam restrições em sua interpretação, como ficou claro neste experimento.

Foi observada resposta da soja, em produtividade, até $1,0 \mathrm{~kg} \mathrm{ha}^{-1}$ de $\mathrm{B}$, mas os teores de $\mathrm{B}$ determinados nas folhas responderam à adubação boratada até $7,5 \mathrm{~kg} \mathrm{ha}^{-1}$ e foram, em média, crescentes com o tempo
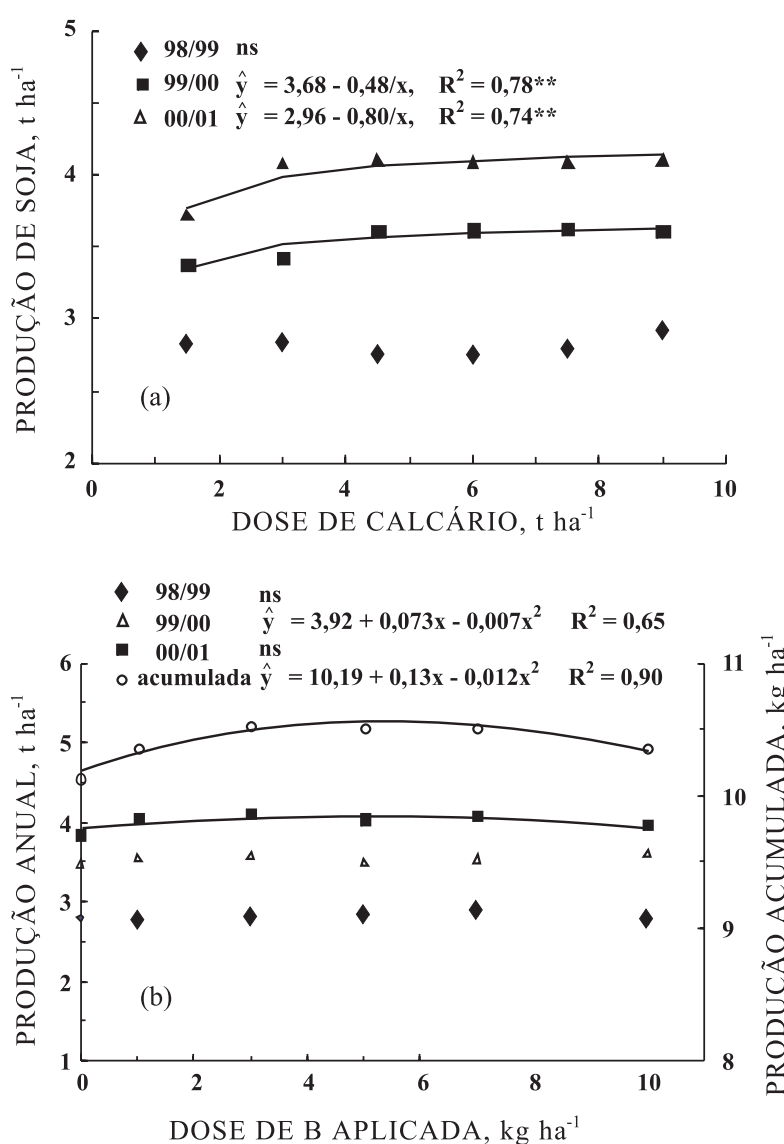

Figura 1. Produção de soja em função da calagem (a) e da adubação boratada (b) nos três anos do experimento. Para calagem, os dados se referem à média de seis doses de boro, e a resposta foi significativa pelo teste $\mathrm{t}(\mathrm{p}<0,05)$ até $4,5 \mathrm{t} \mathrm{ha}^{-1}$ no segundo e $3,0 \mathrm{t} \mathrm{ha}^{-1}$ no terceiro ano.

Quadro 1. Teores médios de fósforo, potássio e matéria orgânica no solo antes da semeadura da soja. Média de seis doses de $\mathrm{B}$ e seis doses de calcário

\begin{tabular}{|c|c|c|c|}
\hline Safra & Fósforo ${ }^{(1)}$ & Potássio & Matéria orgânica \\
\hline & $\mathrm{mgdm} \mathrm{m}^{-3}$ & $\mathrm{mmol}_{\mathrm{c}} \mathrm{dm}^{-3}$ & $\mathrm{~g} \mathrm{dm}^{-3}$ \\
\hline 98/99 & $5,6 \quad(1,7)^{(2)}$ & $43 \quad(3,8)$ & $310 \quad(1,9)$ \\
\hline $99 / 00$ & $6,9 \quad(2,1)$ & $54(5,8)$ & $290 \quad(0,9)$ \\
\hline $00 / 01$ & $6,3 \quad(1,8)$ & $76(13,1)$ & $270 \quad(4,5)$ \\
\hline
\end{tabular}

(1) Mehlich-1. ${ }^{(2)}$ Números entre parênteses indicam o desvio-padrão da média. 

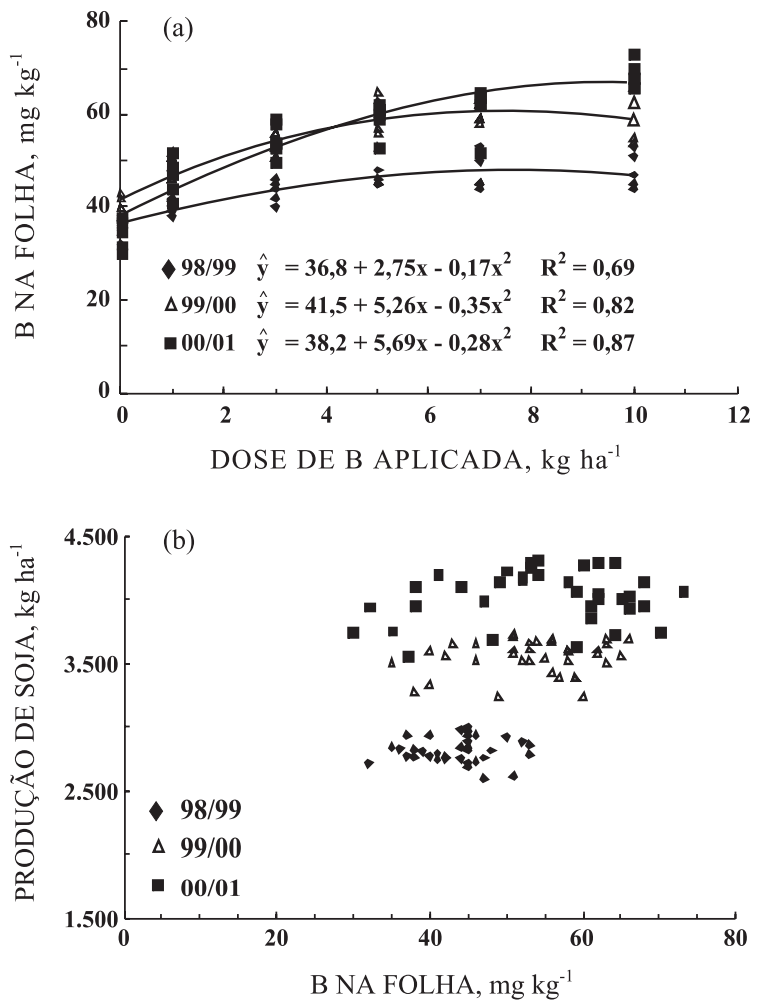

Figura 2. Teor de boro nas folhas de soja (a) em função da dose do nutriente aplicada, e produção de soja em função dos teores de B nas folhas (b). As produções representam a média de seis doses de calcário aplicadas no primeiro ano do experimento.

(Figura 2a), provavelmente em função da menor adsorção do elemento, como observado neste solo por Rosolem \& Bíscaro (2007). Dessa forma, infere-se que o nutriente proveniente do adubo esteve disponível para as plantas durante todo o período experimental. Por outro lado, a resposta quadrática dos teores de B nas folhas da soja às doses do nutriente aplicado pode ser conseqüência da lixiviação do elemento adicionado como adubo, que é maior quanto maior a dose aplicada (Rosolem \& Bíscaro, 2007). Quando se analisou a relação entre os teores de $B$ nas folhas e a produtividade, não houve valores significativos para as regressões (Figura 2b). Considerando-se que os teores de $\mathrm{B}$ se encontravam dentro da faixa adequada (Rosolem, 2007) e que houve resposta da soja ao B aplicado, embora pequena, pode-se concluir que a diagnose foliar, como realizada, não indicou de modo exato o estado nutricional da planta com relação ao B.

Embora tenha sido sempre observada regressão significativa entre as doses de B aplicadas e absorção de B pela planta, o mesmo não foi observado para os teores de B no solo determinados pelos extratores com as doses aplicadas (Figura 3), demonstrando que nem sempre o extrator foi capaz de mostrar o aumento na disponibilidade do nutriente. Assim, no primeiro ano, a correlação somente foi significativa para o $\mathrm{CaCl}_{2}$.
No segundo ano, não foram observadas correlações significativas e, no terceiro, os três extratores (água quente tradicional, $\mathrm{CaCl}_{2}$ e $\mathrm{BaCl}_{2}$ ) foram capazes de revelar aumento na disponibilidade do $\mathrm{B}$ no solo. Tomando-se como referência o valor de $0,5 \mathrm{mg} \mathrm{kg}-1$ como crítico (Embrapa, 2006), sem aplicação de B, todos os extratores indicaram haver possibilidade de resposta ao nutriente, pois mostraram teores menores que o valor crítico, o que de fato ocorreu. Por outro lado, com a aplicação de 1,0 $\mathrm{kg} \mathrm{ha}^{-1} \mathrm{de} \mathrm{B}$, já foi atingida a produtividade máxima em cada ano, enquanto os extratores continuavam a mostrar teores de B no solo menores que 0,5 $\mathrm{mg} \mathrm{kg}^{-1}$ (Figura 3). Assim, analisando-se os resultados apenas por este ângulo, apesar de as extrações de $\mathrm{B}$ do solo com soluções de $\mathrm{BaCl}_{2}$ ou $\mathrm{CaCl}_{2}$ serem utilizadas com sucesso (Abreu \& Abreu, 2001; Ferreira et al., 2001), nenhum dos extratores estaria fornecendo, neste caso, resultados

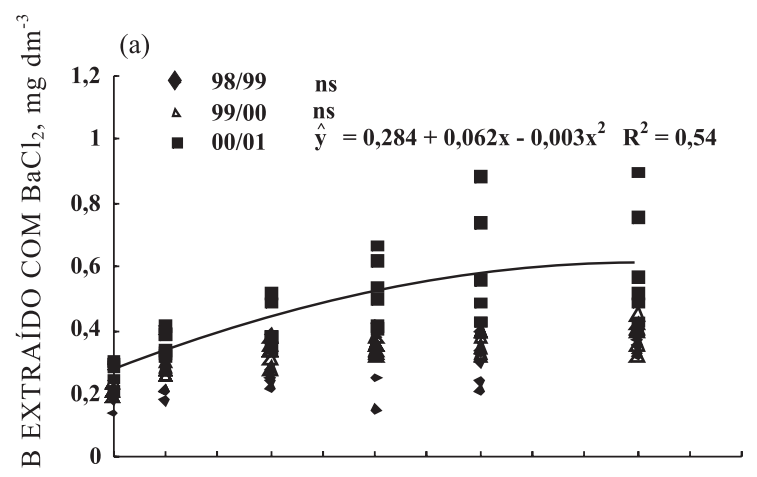

(b)

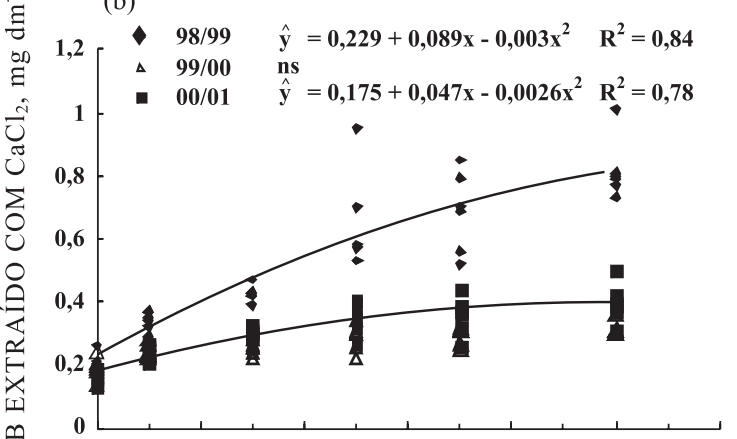

(c)

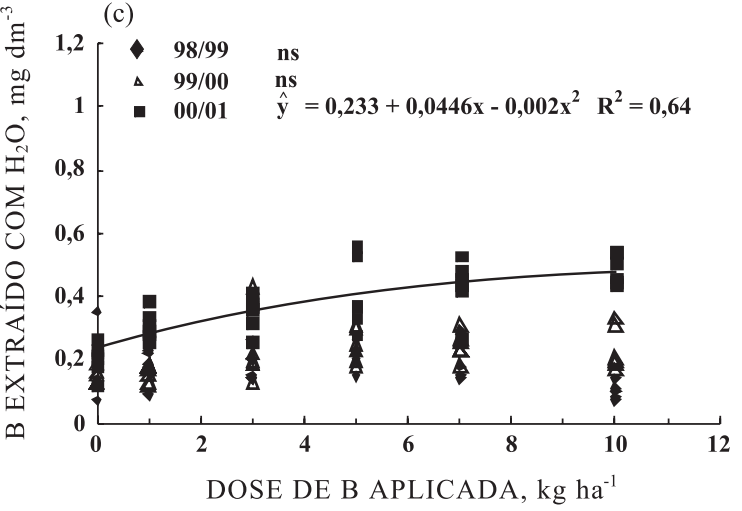

Figura 3. Teor de boro no solo em função da dose de boro aplicada no primeiro ano do experimento. 
plenamente confiáveis para a recomendação da adubação boratada. Provavelmente, isso ocorre devido à lixiviação do nutriente no perfil do solo, abaixo da camada arável (Rosolem \& Bíscaro, 2007).

No ano agrícola 1998/1999 (Figura 4a), os métodos da água quente com solução de $\mathrm{CaCl}_{2}$ e o método da água quente tradicional apresentaram regressão positiva e significativa com o conteúdo de B presente no tecido vegetal, mas o coeficiente da determinação foi maior para o $\mathrm{CaCl}_{2}$. Na safra 1999/2000 (Figura 4b), correlações positivas e significativas foram obtidas para os três métodos; entretanto o coeficiente obtido para o método da água quente tradicional foi bem mais baixo, apesar de também ser significativo a $1 \%$. Para o ano agrícola 2000/2001 (Figura 5a), também foram obtidas correlações significativas $(p<0,01)$ e positivas para todos os métodos testados, sendo o maior coeficiente obtido com método do $\mathrm{CaCl}_{2}$. Quando os resultados dos três anos foram combinados, os coeficientes de determinação encontrados foram menores e significativos apenas para os métodos com $\mathrm{BaCl}_{2}$ e $\mathrm{CaCl}_{2}$ (Figura 5b).
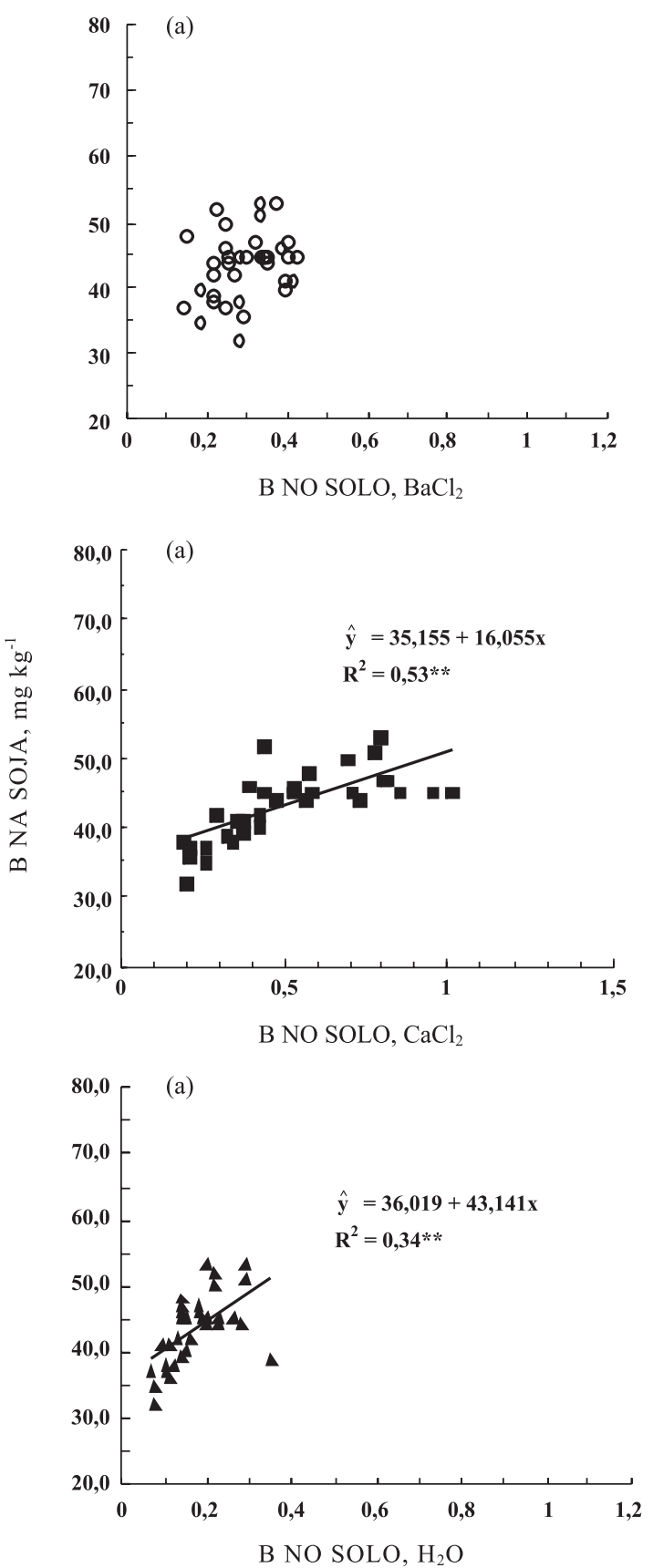
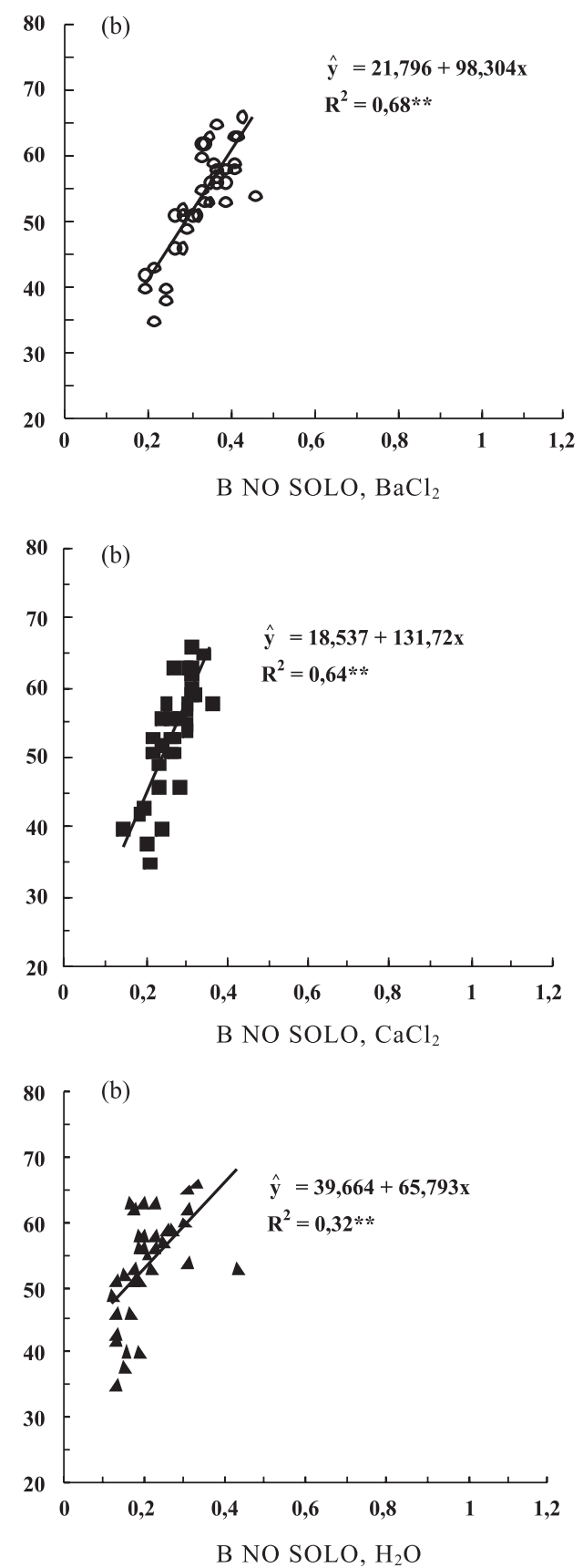

Figura 4. Teor de boro em folhas de soja em função de teores de B no solo, determinados com diversos extratores. (a) safra 1998/1999; (b) safra 1999/2000. 

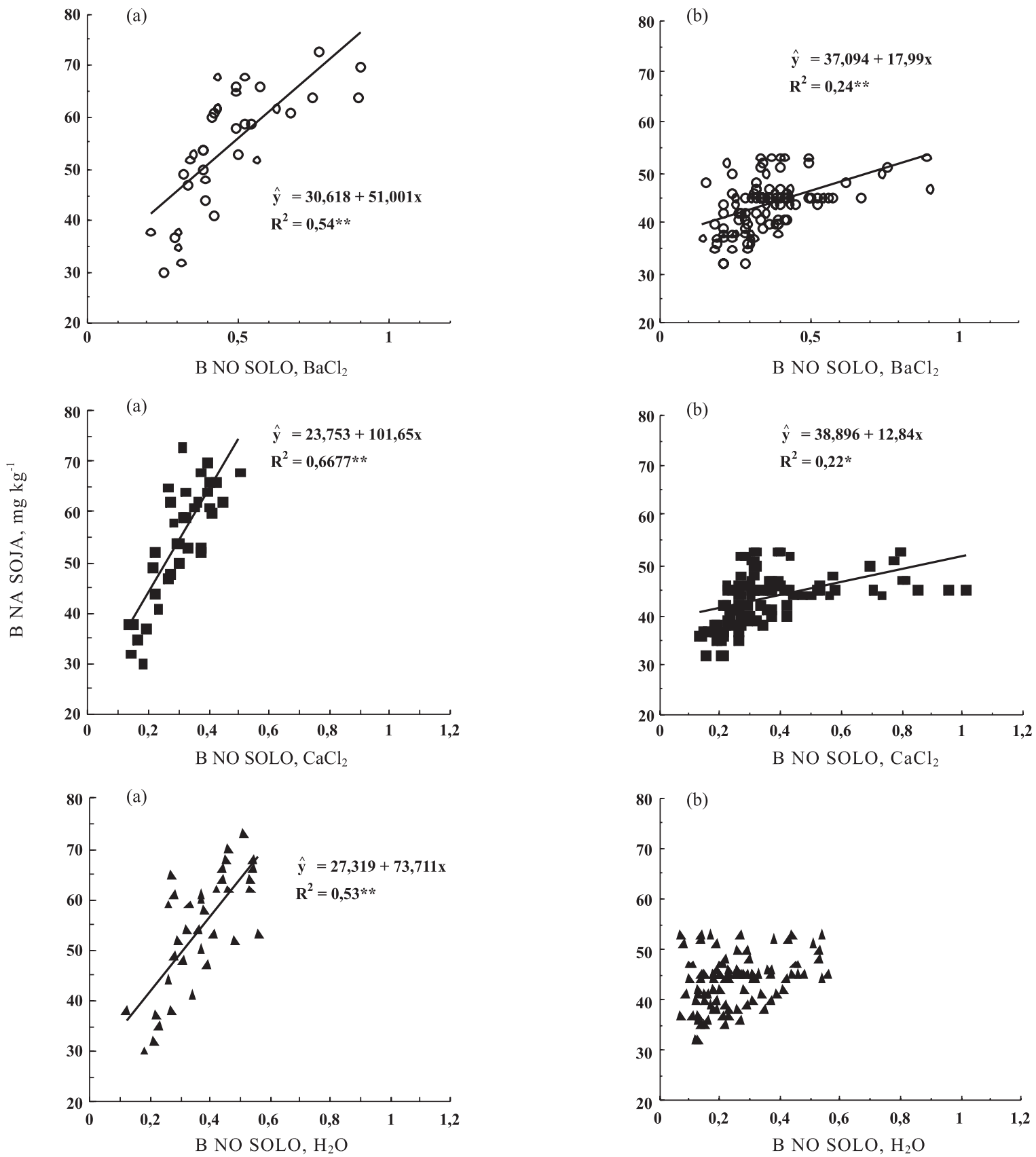

Figura 5. Teor de B em folhas de soja, em função de teores de B no solo, determinados com diversos extratores. (a) safra 2000/2001; (b) dados gerais para as três safras.

O extrator que apresentou maiores correlações significativas com os maiores coeficientes de determinação, nas três safras, foi o $\mathrm{CaCl}_{2}$ a quente. $\mathrm{O}$ método da água quente com solução de $\mathrm{BaCl}_{2} \mathrm{em}$ forno de microondas mostrou resultados semelhantes aos do $\mathrm{CaCl}_{2}$ a quente, com exceção do primeiro ano, quando a adsorção de B pelo solo provavelmente foi maior, pois foi o ano em que o calcário foi aplicado (Rosolem \& Bíscaro, 2007). Assim, esta superioridade do método do $\mathrm{CaCl}_{2}$ pode ter ocorrido em função da maior capacidade do $\mathrm{Cl}^{-}$em extrair a fração dissociada do $\mathrm{B}(\mathrm{OH})_{3}$ adsorvida às cargas positivas dos colóides
(Ferreira et al., 2001) e à competição por sítios de adsorção entre os ânions $\mathrm{Cl}^{-} \mathrm{e} \mathrm{B}(\mathrm{OH})_{4}{ }^{-}$na solução antes da filtração (Jeffrey \& McCallum, 1988). Deve-se considerar, também, que a força iônica da solução de $\mathrm{CaCl}_{2}$, comparada com a da água quente, diminui a atividade do $\mathrm{B}(\mathrm{OH})_{3}{ }^{0}$ na solução extratora, dificultando sua readsorção e favorecendo maior concentração no extrato. Resultados semelhantes têm sido observados (Bataglia \& Raij, 1990; Abreu et al., 1994; Ferreira, et al., 2001), nos quais o método do $\mathrm{CaCl}_{2}$ a quente se mostrou bastante eficiente na determinação do B no solo. 
O método da água quente tradicional também mostrou correlações significativas, como observado por Robertson et al. (1975), embora os coeficientes de determinação tenham sido mais baixos em relação aos outros dois métodos. Ainda, de acordo com Bataglia \& Raij (1990), esse resultado poderia ser esperado, em função da grande semelhança com os outros dois métodos, pois partem do um mesmo princípio e já foram adaptados com a substituição de vidraria por sacos plásticos selados e utilização de aquecimento em microondas.

O bom extrator deve discriminar teores do elemento disponível no solo, correspondente a diferentes produtividades em diferentes situações e, ainda, refletir a adição de fertilizantes. De posse dessa discriminação, os resultados devem permitir a calibração, ou seja, o estabelecimento da dose de adubo de acordo com os teores do elemento no solo (Malavolta, 2006). De acordo com estes princípios gerais, o $\mathrm{CaCl}_{2}$ mostrou aumentos nos teores de $\mathrm{B}$ disponível em função da adição do adubo de forma mais consistente que os outros extratores, ou seja, em dois anos de três analisados (Figura 3). Quando foram analisadas as correlações entre os teores no solo e na planta, novamente o $\mathrm{CaCl}_{2}$ mostrou-se mais consistente, embora os coeficientes de determinação tenham sido baixos quando se consideraram todos os resultados dos três anos (Figuras 4 e 5). Quando foram correlacionados os teores de B no solo com a produtividade de soja, não houve resultados significativos para cada um dos anos e extratores (Figura 6). Se forem considerados os resultados conjuntos dos três anos, poderia haver correlações significativas para o $\mathrm{BaCl}_{2}$ e para a água quente tradicional. Sabe-se que havia outros fatores interferindo na produtividade, o que não permite, no caso, o estabelecimento de causa e efeito entre nutrição boratada e produtividade. Considerando-se o valor crítico de $0,2 \mathrm{mg} \mathrm{dm}^{-3}$ como o teor abaixo do qual haveria resposta da soja ao B (Rosolem et al., 2001), no primeiro ano do experimento os três extratores indicavam a possibilidade de resposta, o que não ocorreu por deficiência de $\mathrm{P}$ (Quadro 1) ou adsorção do B aplicado (Rosolem \& Bíscaro, 2007). De qualquer modo, os extratores não discriminaram a possibilidade de resposta. Mesmo se for considerado o valor de $0,5 \mathrm{mg} \mathrm{dm}^{-3}$ como crítico (Embrapa, 2006), os extratores falharam na discriminação.

Com relação à calibração dos resultados, de modo a permitir a recomendação de doses de fertilizante boratado, nenhum dos extratores proporcionou resultado adequado, uma vez que não foi observada correlação dos teores determinados no solo com a produtividade de soja. Assim, embora tenham sido observadas relações entre a absorção de B pela planta com os teores do nutriente no solo, não houve correlação com a produtividade. Desse modo, pode-se levantar a hipótese de que o horizonte diagnosticado em uso não é o mais adequado para o estabelecimento de níveis críticos de resposta, ou seja, seria interessante o estudo da amostragem de B abaixo da camada arável.
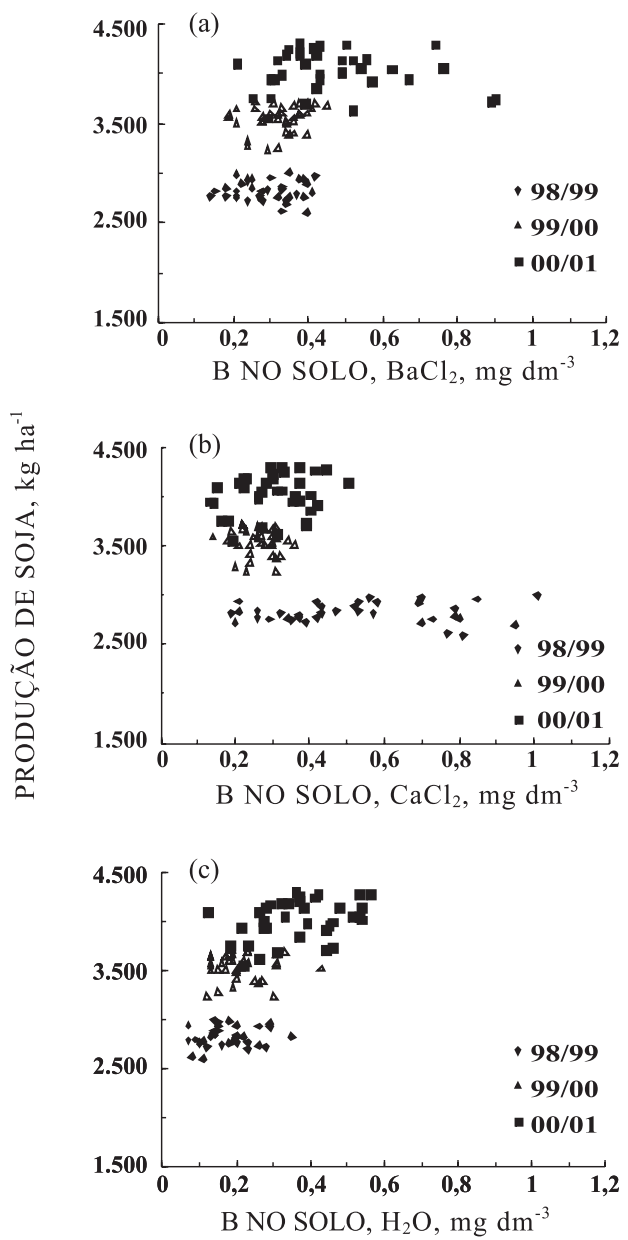

Figura 6. Produção de soja em função dos teores de B no solo, nos três anos de realização do experimento, para os três extratores. (a) $\mathrm{BaCl}_{2}$; (b) $\mathrm{CaCl}_{2}$; (c) $\mathrm{H}_{2} \mathrm{O}$.

\section{CONCLUSÕES}

1. A extração do $\mathrm{B}$ do solo por meio de $\mathrm{CaCl}_{2}$ a quente proporcionou a melhor previsão de absorção de B pela soja, além de apresentar maior consistência de resultados em diferentes anos e situações.

2. Considerando-se a amostragem na camada de 0 a $15 \mathrm{~cm}$ do solo, nenhum dos três métodos mostrou resultados que permitissem a discriminação da resposta da soja, em termos de produtividade, em função dos teores de B no solo.

\section{LITERATURA CITADA}

ABREU, C.A. \& ABREU, M.F. Determinação de boro em água quente usando aquecimento com microonda. In: RAIJ, B. van; ANDRADE, J.C.; CANTARELLA, H. \& QUAGGIO, J.A. Análise química para avaliação de solos tropicais. Campinas, Instituto Agronômico de Campinas, 2001. p.231-239. 
ABREU, C.A.; ABREU, M.F.; RAIJ, B.van; BATAGLIA, O.C. \& ANDRADE, J.C. Extraction of boron from soil by microwave heating for ICP-AES determination. Comm. Soil Sci. Plant Anal., 25:3311-3333, 1994.

BATAGLIA, O.C. \& RAIJ, B.van. Eficiência de extratores na determinação de boro em solos. R. Bras. Ci. Solo, 14:2531, 1990.

BARTZ, H.R. \& MAGALHÃES, A.F. Avaliação da disponibilidade de boro através de soluções extratoras em alguns solos do Rio Grande do Sul. Agron. Sulriograndense, 11:89-96, 1975.

BERGER, K.C. \& TRUOG, E. Boron tests and determination for soil and plants. Soil Sci., 57:25-36, 1944.

BÍSCARO, T. Avaliação da disponibilidade de boro em um Latossolo de Mato Grosso. Botucatu, Universidade Estadu`1al Paulista, 2005. 60p. (Dissertação de Mestrado)

CRUZ, M.C.P. \& FERREIRA, M.E. Seleção de métodos para avaliação do boro disponível em solos. Pesq. Agropec. Bras., 19:1457-1464, 1984.

EMPRESA BRASILEIRA DE PESQUISA AGROPECUÁRIA EMBRAPA. Centro Nacional de Pesquisa de Solos. Sistema brasileiro de classificação de solos. Brasília, Embrapa Produção de Informação, 1999. 412p.

EMPRESA BRASILEIRA DE PESQUISA AGROPECUÁRIA . EMBRAPA. Tecnologias de produção de soja - Região Central do Brasil - 2007. Londrina, Embrapa Soja/ Embrapa Cerrados/Embrapa Agropecuária Oeste, 2006. (Sistema de Produção, 11)

FERREIRA, G.B. Interferências de matéria orgânica e ferro na dosagem de boro com azometina-H e comparação de extratores para boro disponível no solo. Viçosa, MG, Universidade Federal de Viçosa, 1998. 97p. (Dissertação de Mestrado)

FERREIRA, G.B.; FONTES, R.L.F.; FONTES, M.P.F. \& ALVAREZ V., V.H. Influência de algumas características do solo nos teores de boro disponível. R. Bras. Ci. Solo, 25:93-103, 2001.

FONTES, R.L.F.; ABREU, C.A. \& ABREU, M.F. Disponibilidade e avaliação de elementos aniônicos. In: FERREIRA, M.E.; CRUZ, M.C.P.; RAIJ, B.van. \& ABREU, C.A., eds. Micronutrientes e elementos tóxicos na agricultura. Jaboticabal, CNPq/ FAPESP/POTAFOS, 2001. p.187-198.

FUNDAÇÃO MT. Boletim de pesquisa de soja. Rondonópolis, Fundação de Apoio à Pesquisa Agropecuária de Mato Grosso, 2002. p.229-230. (Número, 6)
JEFFREY, L.E. \& McCALLUM, L.E. Investigation of a hot $0,01 \mathrm{M} \mathrm{CaCl}_{2}$ soil boron extraction procedure gollwed by ICP-AES analyis. Comm. Soil Sci. Plant Anal., 19:663673, 1988.

LI, R. \& GUPTA, U.C. Extraction of soil boron for predicting its availability to plants. Comm. Soil Sci.Plant Anal., 22:1003-1012, 1991.

MALAVOLTA, E. Manual de nutrição de plantas. Piracicaba, Ceres, 2006. 631p.

MALAVOLTA, E.A.; VITTI, G.C. \& OLIVEIRA, S.A. Avaliação do estado nutricional das plantas: Princípios e aplicações. Piracicaba, Potafós, 1997. 201p.

MARTENS, D.C. Plant availability of extractable boron, copper and zinc as related to selected soil properties. Soil Sci., 106:23-28, 1968.

OFFIAH, O.O. \& AXLEY, J.H. Soil testing for boron on acid soils. In: GUPTA, U.C., ed. Boron and its role in crop production. Boca Raton, CRC Press, 1993. p.105-123.

PARKER, D.R. \& GARDNER, E.H. Factors affecting the mobility and availability of boron in some Western Oregon soils. Soil Sci. Soc. Am. J., 46:573-578, 1982.

PINAZZA, L.A. \& BORSARI, F. Aumenta o uso de micronutrientes. Agroanalysis, 84:50-51, 2004.

RIBEIRO, A.C. \& TUCUNANGO-SARABIA, W.A. Avaliação de extratores para zinco e boro disponíveis em Latossolos do Triângulo Mineiro. R. Bras. Ci. Solo, 8:85-89, 1984.

ROBERTSON, L.S.; KNEZEK, B.D. \& BELO, J.O. A survey of Michigan soils as related to possible boron toxicities. Comm.Soil Sci.Plant Anal., 6:359-73, 1975.

ROSOLEM, C.A. Produtividade máxima da soja. Rondonópolis, Fundação MT, 2007. p.237-244. (Boletim de Pesquisa de Soja)

ROSOLEM, C.A.; QUAGGIO, J.A. \& SILVA, N.M. Algodão, amendoim e soja. In: FERREIRA, M.E., CRUZ, M.C.P.; RAIJ, B.van \& ABREU, C.A. Micronutrientes e elementos tóxicos na agricultura. Jaboticabal, CNPq/FAPESP/ Potafós, 2001. p.319-354.

ROSOLEM, C.A. \& BÍSCARO, T. Adsorção e lixiviação de boro em Latossolo Vermelho-Amarelo. Pesq. Agropec. Bras., 42:1473-1478, 2007.

SILVA, F.R. \& FERREIRA, H.F.F. Disponibilidade de boro em solos do Estado do Ceará. R. Bras.Ci.Solo, 23:227-236, 1999 .

ZARCINAS, B.A. Supression of iron interference in the determination of boron using the azomethine-H procedure. Comm.Soil Sci.Plant Anal., 26:713-729, 1995. 